Short Communication

\title{
Resistance of the $S_{1}$ layer in kempas heartwood fibers to soft rot decay
}

\author{
Adya P. Singh ${ }^{1}$, Andrew H.H. Wong ${ }^{2}$, Yoon Soo Kim*, and Seung Gon Wi \\ Department of Wood Science and Engineering, Chonnam National University, Gwangju, \\ South Korea \\ ${ }^{1}$ Permanent address: SCION, Rotorua, New Zealand \\ ${ }^{2}$ Permanent address: Faculty of Resource Science and Technology, University Malaysia- Sarawak, \\ Sarawak, Malaysia \\ *Corresponding author; e-mail: kimys@chonnam.ac.kr \\ Accepted for publication: 13 June 2017
}

\begin{abstract}
Naturally durable heartwoods, where available, continue to be used as support structures in environments considered hazardous, particularly in ground contact. However, durability of heartwoods against wood decay microorganisms varies. Therefore, it is important to evaluate heartwood products for their in-service performance in order to maximise benefits derived from this valuable natural resource of limited supply. In the work presented, wood pieces from a kempas (Koompassia malaccensis) utility pole that had been placed in service in an acidic soil in Malaysia, and in time had softened at the ground-line position, were examined by light and transmission electron microscopy to evaluate the cause of deterioration.

Light microscopy (LM) provided evidence of extensive attack on fibre cell walls by cavity-producing soft rot fungi. Transmission electron microscopy (TEM) revealed in greater detail the distribution and micromorphologies of cavities as well as their relationships to the fine structure of fibre cell walls, which consisted of a highly electron dense middle lamella, a moderately dense $S_{1}$ layer and a multilamellar $S_{2}$ layer with variable densities, reflecting differences in lignin concentration. The resistance of the moderately dense $S_{1}$ layer to soft rot was a feature of particular interest and is the main focus of the work presented. The resistance appeared to be correlated with high lignification of the outermost region of the $S_{2}$ wall, interfacing with the $S_{1}$ layer, an unusual cell wall feature not previously described for normal wood.
\end{abstract}

Keywords: Koompassia malaccensis, kempas heartwood, soft rot cavities, cell wall lignification, multilamellar $\mathrm{S}_{2}$ layer, LM, TEM. 